\title{
pH and Temperature Thermosensitive for Modification of Cotton Fabric (A Review)
}

\author{
Doaa M. Hamdy ${ }^{1}$, Ahmed. G. Hassabo ${ }^{2, *}$ (D) \\ 1 Textile Printing, Dyeing and Finishing Department, Faculty of Applied Arts, Benha University, Benha, Egypt \\ 2 National Research Centre, Textile Industries Research Division, Pretreatment, and Finishing of Cellulose-based Textiles \\ Department, 33 El-Behouth St. (former El-Tahrir str.), Dokki, P.O. 12622, Giza, Egypt \\ * Correspondence: aga.hassabo@ hotmail.com;
}

Scopus Author ID 55909104700

Received: 19.03.2021; Revised: 28.05.2021; Accepted: 2.06.2021; Published: 18.06.2021

\begin{abstract}
Because of their unusual properties, Hydrogels have been one of the most exciting areas within the drug system. Responsive hydrogels gave the delivery system excellent spatial and temporal power with gelation at physiological temperature. In different medical applications such as sensors, drug release systems, and so on, SRHs have been used. Other fields such as practical textiles and clever garments also undergo active study. The research covers the use of biotherapy molecules in temperature-sensitive gel systems.
\end{abstract}

Keywords: hydrogels; temperature-sensitive gel; $\mathrm{pH}$ and temperature thermosensitive.

(C) 2021 by the authors. This article is an open-access article distributed under the terms and conditions of the Creative Commons Attribution (CC BY) license (https://creativecommons.org/licenses/by/4.0/).

\section{Introduction}

During these last few years, hydrogel forms have been studied for applications, ranging from the isolation of solution to a regulated solution distribution, shows a substantial swelling in the reaction to an external stimulus such as ionic strength, $\mathrm{pH}$ temperature, and electrical potential [1-5]. Hydrogels that have demonstrated swellability in specific temperatures and $\mathrm{pH}$ to more than one component have recently been investigated [6]. These experiments indicate that $\mathrm{pH}$ and temperature affect gel swelling separately and jointly [7]. Both $\mathrm{pH}$-dependent temperature swelling shifts and vice versa, the data show. Hydrophilic polymer networks that include $\mathrm{pH}$ and temperature-sensitive elements are $\mathrm{pH} /$ temperature-sensitive hydrogels [8]. The thermosensitive components are normally monomers, which display a lower critical solution (LCST) temperature in the water when polymerized [8]. The $\mathrm{pH}$-sensitive part is an ionizable monomer that contributes to a $\mathrm{pH}$-dependent swelling if inserted into a gel due to its strong effect on gel swelling [9]. This analysis aims to establish the magnitude of $\mathrm{pH}$ and temperature swelling by the responsive hydrogels and explain mutual control mechanisms [8].

Many polymers for the supply of biotherapeutics have been applied to advance materials science and technology [2,10-16]. Hydrogels, with a cross-linked three-dimensional structure, consist of hydrophilic polymers capable of captivating water without being dissolved, have gained significant interest in the past decades relative to other engineered biomaterials because their physical characteristics mimic living tissues. Hydrophilic groups such as an amine $\left(-\mathrm{NH}_{2}\right)$, carboxylic $(-\mathrm{COOH})$, and sulfate $\left(-\mathrm{SO}_{3} \mathrm{H}\right)$ groups in hydrophilic groups give these three-dimensional cross-linking polymers excellent water locking capabilities and a water soaking rate that can vary from 100 to more than a thousand times their weight $[8,17-19]$. 
Of special interest, rheological, mechanical properties are closer to solids, identical to the biological tissue, for hydrogels that store large-volume water and thus promote the imitation of natural tissue [20]. Chemically or mechanically, the intertwined nature of hydrogels offers distinctive swelling behavior [21]. Hydrogels can make reversible floating and de-swelling, and their swelling properties are closely linked, in turn to a collapse or a phase shift in the external environment such as $\mathrm{pH}$, temperature, and ionic concentration. [22-24].

The classification of hydrogels is varied, for example, according to the source (natural and synthetic polymer), cross-linking (chemical and physical), physical shape (amorphous, super-molecular, hydrogen bone, semicrystalline), ion load (anionic, cationic, ampholytic, and non-ionic, microgel, nanogel) and biodegradability(non-degradable and degradable (nondegradable and degradable) $[25,26]$.

Common hydrogel experiments previously focussed on chemicals that link to permanent gels before surgery [18]. These hydrogels are widely used for implantable surgical applications [19]. The use of toxic and cross-linking catalysts in this permanent interlinking mechanism will harm and cause low biocompatibility of therapeutic molecules such as proteins or cells [17]. Moreover, conventional hydrogels have an insufficient mechanical ability, which is an intelligent response to external stimuli, creating major limitations in practical usage $[1,27]$.

Therefore, the creation of intelligent gels that respond to the atmosphere has become a hot area [28]. In several areas such as pharmaceutical products, biosensors, drug supply water treatment, and soil water conservation, intelligent hydrogens were created, capable of reacting to such factors as temperature, $\mathrm{pH}$, light, and more [20]. Environmental stimuli outside pacemakers grade resistant hydrogens as thermo-sensitive, $\mathrm{pH}$-sensitive, electrosensitive as well as light-sensitive, pressure, and ionic resistance [19]. In physiological settings, hydrogels, developed de novo, draw more concern while reducing the chances of surgical settlement such as cavities and infection [17,29,30].

Thermo-reactive hydrogels are the most studied polymer structures since the normal and easy-to-control temperature varies. The sum of thermal sensitive hydrogels (swelling/deswelling) and the transmission of hydrogels react intelligently with the temperature variety [10]. In systems, hydrophobic and hydrophilic elements are usually found in temperaturesensitive hydrogels. The thermal reaction phenomena derive from the delicate equilibrium between the hydrophobic and the hydrophilic parts $[1,18]$. Temperature affects the interaction among the hydrophilic and hydrophobic segments of the polymer with water molecules, so the solubility of the connected network will change, triggering the transition from the sol-gel process [31]. The sol phase is described as fluid, while the gel phase is not fluidized and maintains its completeness [1,22].

Changes in hydrophilicity and hydrophobicity equilibrium can decide the dissolved macro size of the cross-linking system. Microscopic processes based on thermosensitive groups can create the freezing property of thermally sensitive hydrogels $[18,30]$.

At lower critical solution temperature (LCST) or higher critical solution temperature, hydrogels display a distinction from the solution and are solid (UCST) [30]. Under LCST, the polymer is soluble, while at a temperature on LCST, it starts to shrink, hydrophobic and insoluble, contributing to gel-forming [7]. The hydrogel developed when the solvent is cooled at a high critical solution temperature, in comparison (UCST) [32]. The polymer in the solution at the critical temperature displays a phase shift from a soluble state (random belt) to an 
insoluble state (collapse or micelle form) [17]. By adjusting the hydrophilic to hydrophobic ratio, the underlying LCST can be set (see Figure 1) [22,23,29].

Because the controllable release of the bioactive agent is sensitive to temperature changes, thermo- sensitive hydrogels have been widely developed [25]. As a delivery system, thermo-sensitive gels have many advantages. The temp-sensitive properties donate the injectability of the hydrogel to local administration, which can prevent the first-pass metabolism, unlike traditional hydrogels $[1,26]$. The temperature-sensitive gel reacts to the temperature and is safer for the body and better for injectable systems because no denaturation cross-link agent is required [21]. Flowing encapsulation permits the even dispersion of therapeutic agents in hydrogels, while rapid sole-to-gel transition in the body at body temperature initially prevents the explosion of the therapeutic agents controlled the release behavior $[10,28,33]$.

Finally, the fluid management state provides the control of the hydrogel shape. This article examines thermosensitive hydrogels and concentrates on their use in biotherapeutic molecule delivery [32].
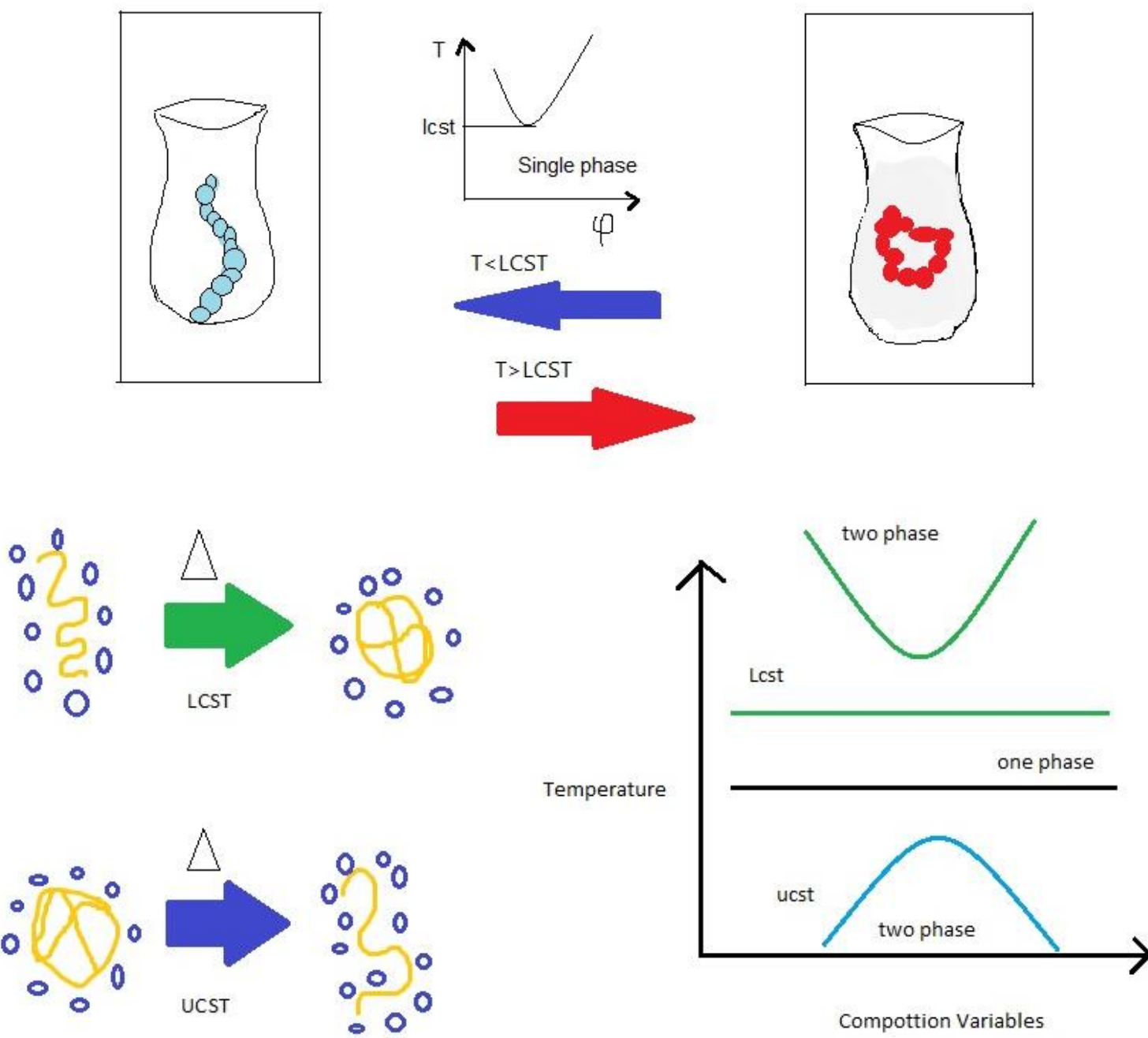

Figure 1. changing the polymer behavior between LCST and UCST. 


\section{Thermosensitive hydrogels classification}

Temperature-sensitive hydrogels can be classified according to their temperaturesensitive composition into thermally-sensitive and positively thermo-sensitive hydrogels. LCST polymers can form hydrogels that are sensitive to the negative temperature and shrink with the temperature rise. Hydrogen connection between polymer chain hydrophilic groups and water molecules is dominant at a lower temperature and contributes to water dissolution $[9,29]$.

However, hydrophobic interactions between hydrophobic groups are increased with temperature, while a weak hydrogen bonding induces gelation [21]. The hydrogen sensitivity to positive temperatures increases their water-solubility with a higher temperature that is UCST. summarizes LCST of several water polymers (see Table 1) [1,22,23].

Table 1. The LCST of aqueous solution polymers [22,33].

\begin{tabular}{l|l} 
Polymers & LCST $\left({ }^{\circ} \mathbf{C}\right)$ \\
\hline Poly(N-isoprolylacrylamide), pNiPAAm & 32 \\
\hline Poly(ethylene glycol), PEG & 120 \\
\hline Poly(propylene glycol), PPG & 50 \\
\hline Poly(methacrylic acid), PMAA & 75 \\
\hline Poly(vinyl alcohol), PVA & 125 \\
\hline Poly(vinyl pyrrolidone), PVP & 160 \\
\hline Methylcellulose, MC & 80
\end{tabular}

The hydrogels that were used in the sample have been synthesized as temperaturesensitive components (NIPAA), pH-sensitive (DEAEMA) [36,37]. Butyl methacrylate (BMA) as a hydrophobic component has been synthesized as a $\mathrm{pH}$-sensitive component, and mechanically stable gels have been hydrophobically increased $[8,10]$.

The effect of the temperature on $\mathrm{pH}$-dependent swelling is demonstrated through a poly(N1PAAm-co-BMA-co-DEAEMA) and non-thermosensitive polymer, PKB of the DEAEMAs, depending on the temperature (acrylamide-co-DEAEMA) [21]. To understand how ionization affects the temperature-dependent swelling of the ionizable component, unconnected analogs of the gels were studied on the LCST $[18,38]$.

The most intensively studied thermo-responsive polymer is poly( $\mathrm{N}$-isopropyl acrylamide) (Poly-NiPAAm) with a volume-phase transition (e.g., side chain dehydration) in response to minor temperature shifts, including in small quantities [20]. Because of the very complex polarity of the molecule, the transition between coil and globule occurs at a temperature of about $32^{\circ} \mathrm{C}$, called a lower critical solution temperature (LCST) $[25,39]$.

Under the LCST the amide Group binds water molecules into an extended structure through hydrogen bonding (i.e., hydrates), which splits through the hydrogen bonding of the LCST, expelling water and precipitating polyp (i.e., its chains dehydrate to form a shrunken structure) $[1,18,34]$.

\subsection{Hydrogel stimulant reaction}

These hydrogels are functional polymers that respond to outside stimuli and change their physicochemical composition, particularly water solubility [22]. These hydrogels are referred to as "intelligent" or "active" hydrogels [7]. The compounds may be $\mathrm{pH}$, temperature, ionic strength, electric and magnetic fields, and compounds such as light, pressure, and chemicals (e.g., glucose) [25]. The modifications in the properties of the hydrogel are typically 
reversible and the mechanism recovers to its original condition when the stimulant is withdrawn [22,36].

In a device, it is possible to modify the molecular relations between polymers and solutes by chemical factors such as $\mathrm{pH}$, biochemical, ionic alteration, or physical stimulus such as temperature, magnetic or electrical fields [21]. These interactions can modify various properties of polymeric hydrogels, such as swelling, solubility, configuration, chain conformation, redox condition, and crystalline and amorphous [1]. We also tried to draw up a panorama of some essential hydrogels that respond to the stimulus used in textiles $[10,22]$.

\subsection{Hydrogels that react to temperature.}

Hydrogels that react to temperatures are classified as Good structures, pessimistic.

- Hydrogel reacts to a negative temperature above its lower critical solution temperature (LCST) [30].

- Hydrogel contracts at positive temperatures below its high critical solution thermal (UCST) (Figure 1) [21].

Among hydrogels sensitive to temperature like

- Poly(N-alkyl acrylamide) poly(ethylene oxide)-poly(N-alkylacrylamide) [6].

- Copolymers, pyrrolidone (propylene oxide) (PEO-PPO) [10].

Cellulosic ethers (PNIPAAm) were the most widely studied poly(N-isopropyl acrylamide) [36]. The hydrogel is fully hydrated and has hydrophilic properties below this temperature and shifts in a solid system after heating over LCST, and exhibits hydrophobic characteristics PNIPAAm has a narrow transition temperature zone around physiologic body temperature $\left(32^{\circ} \mathrm{C}\right)[10]$. Similar temperature-responsive hydrogel properties of PNIPAAm are contained in Poly(N-vinylisobutyramide) with LCST approximately $39^{\circ} \mathrm{C}$ or Poly(n-vinyl caprolactam) LCST approximate to $32-33^{\circ} \mathrm{C}$. The essential temperatures of a thermosensitive hydrogel can be tuned by adding hydrophobic or hydrophilic comonomers to the structure $[10,21,22,35]$.

\subsection{Hydrogel pH-responsive}

In addition to the variation of environmental $\mathrm{pH}$, the shift in volume and properties is the most significant aspect of $\mathrm{pH}$-responsive hydrogels [6]. For 3D networks, at least anionic polymer is required for $\mathrm{pH}$-sensitive hydrogels. The best polymers for the preparation of $\mathrm{pH}$ sensitive hydrogels are polyelectrolytes [30].

These hydrogels may be manufactured from natural or synthetic sources [19]. For starters, ionizable such as $-\mathrm{NH}_{2},-\mathrm{COOH}$ have natural polymers such as chitosan and collagen [7]. In the community of synthetic $\mathrm{pH}$-responsive hydrogels, some of the weak poly acids, weak poly bases, and amphoteric polymers [1]. PAA is the specimen of weak poly acids accepting acid-pH protons and releasing neutral and basic $\mathrm{pH}$ protons. Poly(4-vinylpyrids) is a polybase that is protonated at basic $\mathrm{pH}$ and is positively ionized at lower $\mathrm{pH}$. The influence of $\mathrm{pH}$ shifts on hydrogels sensitive to $\mathrm{pHs}$ is seen in Figure 2. The anions are formed by leaving protons in the polymer chains and allowing a force of repulsion between the chains to swell at this $\mathrm{pH}[10,22,36]$. 


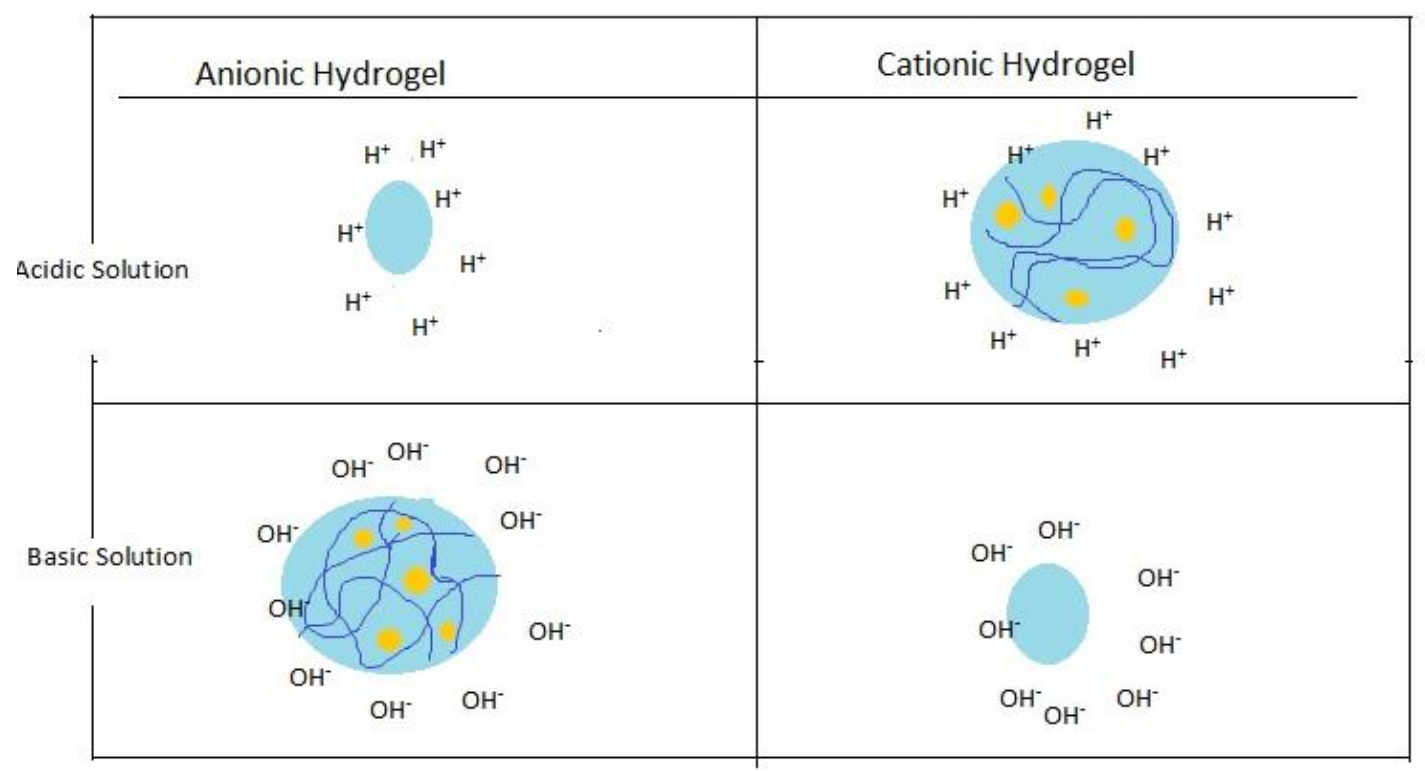

Figure 2. Influence of $\mathrm{pH}$ changes on the responsive hydrogel.

\subsection{Other hydrogels that respond to stimuli.}

Various polymers of various ionic groups can be susceptible to the electrical field due to their ionic charges and electronic fields changing their phase transition behavior[17]. Yuk and Lee showed that electrically receptive hydrogels are influenced by loading density, ionic force, electrical potential, etc. [24]. They suggested a reversible bending method of $\mathrm{NaCl}-$ induced $\mathrm{NaCl}$ solution for cross-linking acrylamide gel [1].

The next group of stimulating hydrogels are photoreaction hydrogels. They typically consist of a 3D polymer network and photo-reactive chromophore groups [19]. They have changed their structures by UV or visible-light irradiation, which leads to changes in the properties of the photosensitive hydrogel. Cis-trans isomerization, roundabouts mechanisms and ionization cause the light sensitivity of these hydrogels [38].

The hydrogel structure and the polymer hydrophilicity are increasing[26]. Typical examples of light-sensitive hydrogels for screens, switches, or drug delivery applications include Poly(N, N-dimethyl-4-phenylazophenyl acrylate), Poly(NIPAAmtriphenylmethaneleuconitrite), or Partially esterified poly(NIPAam-hydroxyethyamide) (Figure 3) [28].

The latest study has been performed on the new principle of bimolecular-sensitive hydrogels in natural systems. Special ions or biomolecules like glucose can be found in these hydrogels and react to them with insulin release [31]. The obligation for glucose is shown by weakly acidic or basic groups in the hydrogel structure in conjunction with glucose oxidase. The oxidation of glucose oxidase reduces the $\mathrm{pH}$ of the solution by the glucose to the glucose acid. It causes hydrogels that carry a weak basis or collapse in hydrogels with weak acid groups to swell [25]. The hydrogel network releases insulin as follows (Figure 4) [8,22].

(1) A permeable membrane which is separating a reservoir of insulin may be used as the hydrogel [26].

(2) The porous hydrogel can also be used structure itself. 

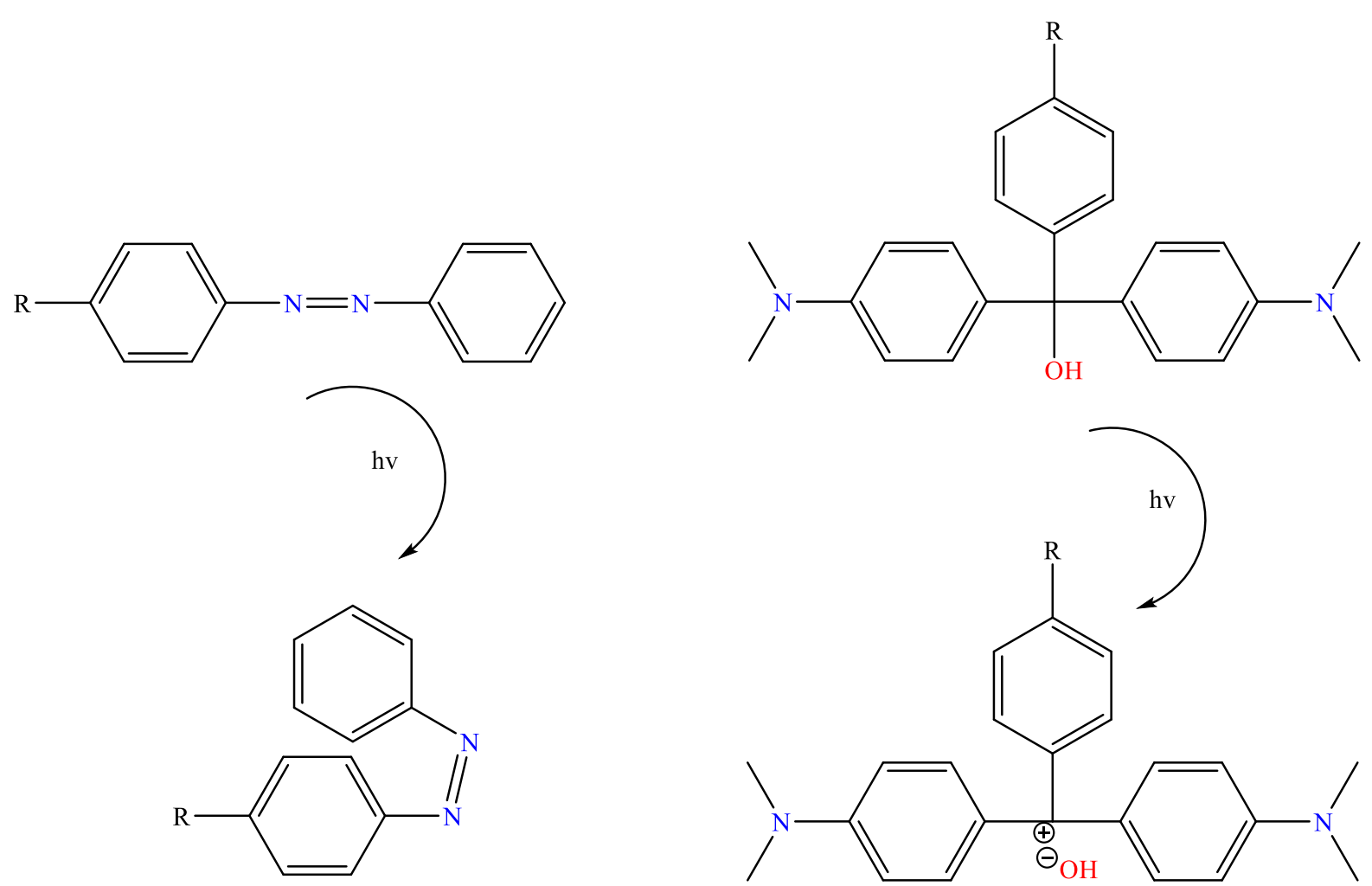

Trans-Azobenzene

Cis- Azobenzene

Triphenylmethane

Figure 3. Some photoactive groups in a photoresponsive hydrogel.
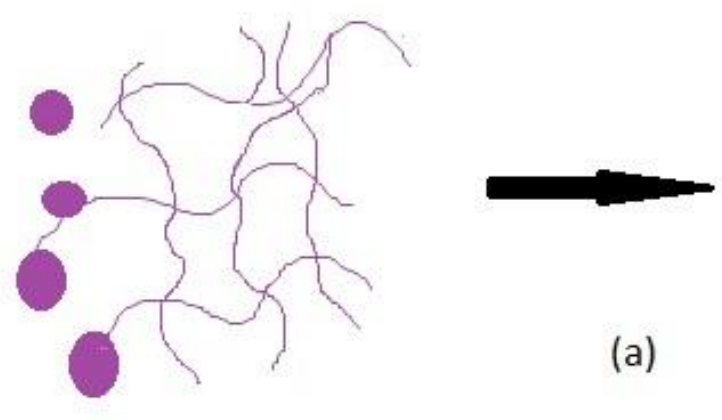

(a)
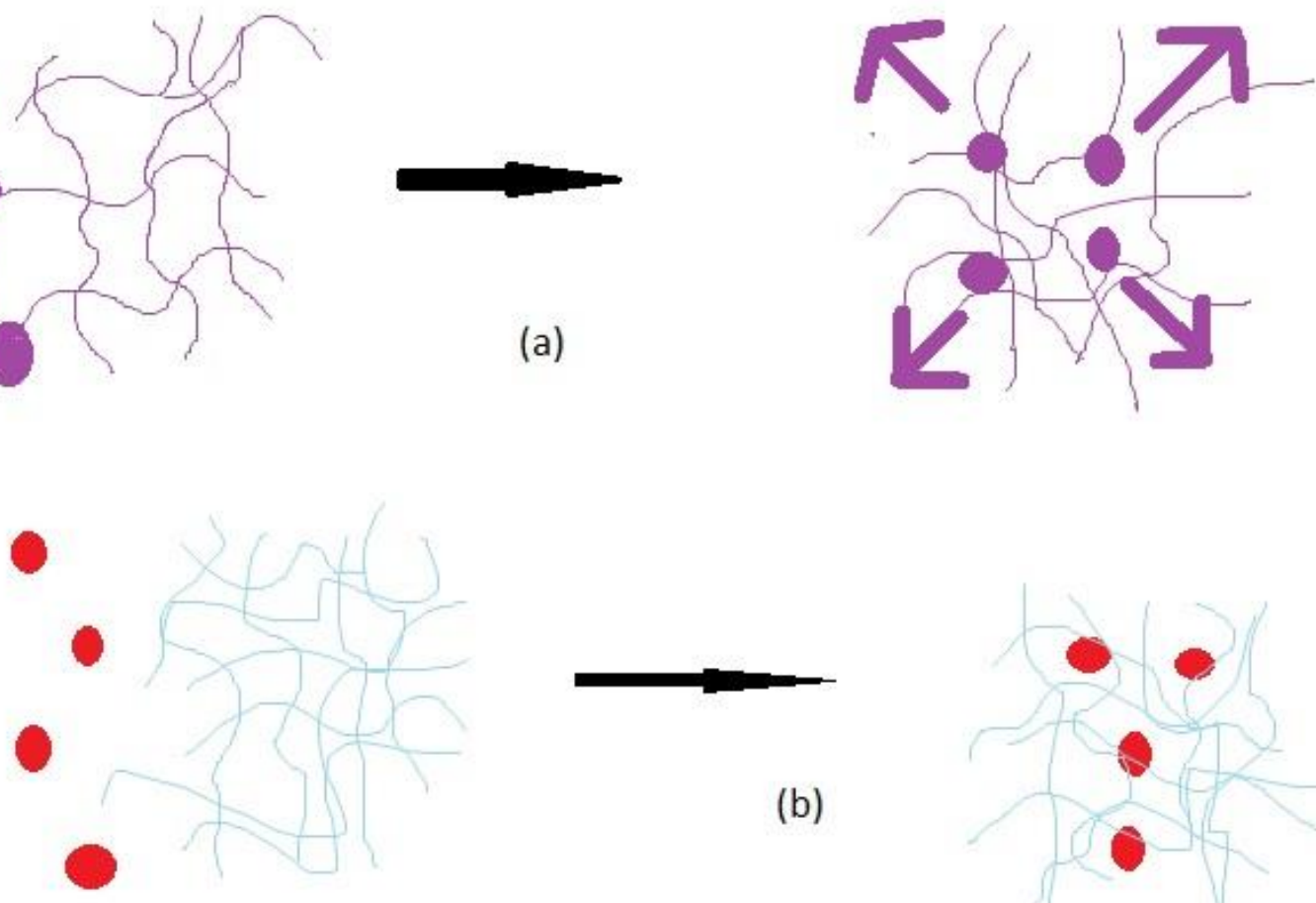

(b)

Figure 4. Insulin release mechanism from glucose responsive hydrogel: a) from hydrogel membrane; b) reservoir role. 


\section{Stimulus reaction hydrogels in Applications Fabric}

Cotton, flax, jute, ramie, and sisal are natural vegetable polymeric cellulose fibers [40,42]. They are excellent natural materials that have been widely used in many fields, especially in the textile industry. These fabrics have good water ability, softness, hygroscopicity, natural durability, and less electricity. It can also be processed to give it a wide variety of colors due to its ability to be dyed in multiple ways. It would be beneficial to impart high-performance properties to natural fibers to functionalize the natural fibers absorption and/or penetration of functional polymeric materials onto/into the fiber surface [12,43-58].

Temperature-responsive, $\mathrm{pH}$-reactive, or temperature- $\mathrm{pH}$ dual hydrogels are the most frequently used hydrogels in textiles. Poly(N-isopropyl acrylamide) (PNIPAAm) is more popular among temperature-sensitive hydrogels than others [35]. As previously mentioned, PNIPAAm has LCST near human body temperature in an aqueous medium of around $32-34^{\circ} \mathrm{C}$ [26]. For smart textile applications, PNIPAAm has therefore been studied. Liu and Hu outlined studies of hygroscopic and stimulating responsive nutrient distribution in China and Japan. [29]

The following group of stimulus-sensitive hydrogels, commonly studied due to their physiological properties, are $\mathrm{pH}-$ responsive hydrogels. These hydrogens, for example, chitosan and polyvinyl alcohol/PAA, typically have weak acid groups, such as carbonyl or alkaline ones, such as amino [1]. Chitosan, a biopolymer with excellent biologic, antibacterial, biocompatible, and biodegradable properties (poly-(N-acetyl-D-glucosamine co-D-glucosamine) is used in textile applications rather than other $\mathrm{pH}$ reactive hydrogels [30].

\section{Tissue engineering stimulus-responsive textiles}

In tissue engineering for human body reconstruction, living cells and their extracellular elements with textile scaffolds are used [30]. The most commonly used fiber-based fabrics are nonwoven textiles that can be biodegradable and avoid a body tissue reaction to external clothing [26]. Zhang and others have developed and synthesized two forms with specific features such as biodegradability, temperature stability, controllable hydrophilicity, and strong mechanical characteristics [17].

The 3-arm, poly-star (social) arm (mother), and glycol center are some of the newest biodegradable hydrogen (Figure 5). The gelatine family with various cross-relationship densities produces another biodegradable polymer [17].

Risbud et al. have designed coated cloth scaffolds for the processing of tissues. In this study, a biologically degradable membrane made of chitosan was covered by woven polyethylene terephthalate (PET) fabric with well-defined macropores [1]. This device has a 3D cell attachment structure. The degradable hydrogel membrane on both sides of the substratum could generate a concentration and pressure gradient, and with biodegradation, the scaffold's diffusion and repulsion properties were modified [37]. They investigated the influence of casting and biodegrading properties on the microstructure of a matrix and stressed the freezing effects on the hydrogel-coated textile scaffolds microstructure [35]. The freezing mechanism caused higher porosity in the hydrogel matrix, and without previous freezing, the non-porous membrane could be reached [25]. 


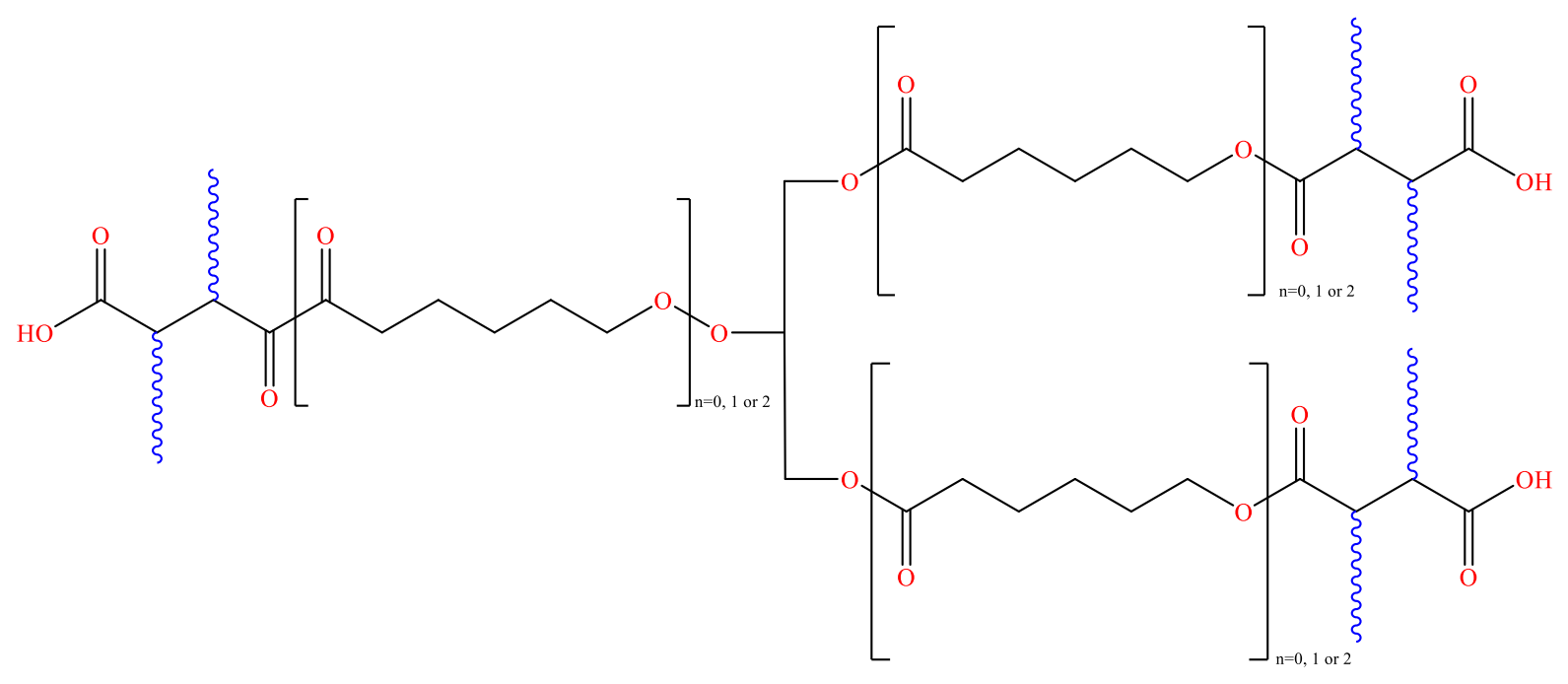

Figure 5. 3-arm, poly-star (social) arm (mother) and glycol center.

\section{Release function of biotherapeutic molecular temperature-dependent hydrogels}

Various model experiments on potential pathways for releasing hydrogel substances can be categorized as [10]: (i) passive diffusion, (ii) hydrogel corrosion, and (iii) chemical regulation. Medicines release mechanisms can be classified [1]. The most common release method of thermally sensitive hydrogels is passive diffusion, and depending on the grid size of the gel matrix, the varying sizes of biotherapeutic molecules that are encased in the gel matrix will disperse freely [29]. The behavior itself has affected many parameters, such as the extent of cross-linking, monomer chemical structure, and external stimulus strength [19]. In swollen, which is far bigger than the majority of smaller molecular drugs, the average mesh size of temperature-sensitive Hydrogels recorded is from 5 to $100 \mathrm{~nm}$ [21].

The diffusion of these medicines is free, while the structure and the size of the swollen hydrogel are properly engineered to meet the optimal diffusion rate, macromolecules like the oligonucleotides, peptides, and proteins show a continuous release. The release of biotherapeutic molecules depends on the erosion rate for the erosion-controlled process [24]. The chemical mediated release is also determined by the chemical reactions between the polymer network and the release of the compound, including polymer chain cleavage by hydrolysis or the enzyme degradation or reversible/irreversible reactions $[1,23]$.

\subsection{Thermal-responsive polymers in textile applications.}

SMPs are some of the thermal-responsive polymers most tested and used (TRPs). SMPs will recall their original forms and swiftly shift their forms under thermal stimulus from a temporary state to their original (or permanent form. Various types of SMPs have already been developed, such as solutions, emulsion, film, fabric, foam, and mass forms that can be properly applied in various circumstances [32]. The SMP can be used in intelligent textures, intelligent medical instruments, heat shrinkable electronic tubing, electrical sensors and actuators, smart water vapor permeability content, aerospatial structures, microsystems, damping products, car parts, dolls, hair treatments, and chemical feeding for chemical reactions [19]. SMPs can be used in the fields of smart clothing and clever medical equipment [31,38].

SMPs based on glass or felting transitions functioning as switches normally have a cross-linking physical structure, an amorphous/crystalline hard phase, a cross-linking chemistry structure, and a crystalline or amorphous transition low temperatures [19]. It is stored 
or set thermally in an "original form. The internal tension is normally negligible or markedly small in the initial set form [10]. The applied stress is deposited in the connection structure as the SMP is subjected to deformation, cooling the polymer underneath its switch transition temperature (SMP) [7]. Thus, owing to the sharp rise in elastic modulus in the glass or fusion transition temperature, the deformed temporary shape is fixed. On heating the polymer above the transition temperature, the SMP regains its permanent form to eliminate the internal tension that the connected framework has retained $[25,30]$.

\subsection{Temperature-sensitive hydrogel applications}

Since the environment in the extracellular matrix is highly cooperative and imitates, hydrogels have become possible candidates for many biomedical applications. Soft lenses, wounds healing, tissue engineering, and sensors are common uses for hydrogels [38]. Instead of basic contact lenses, hydrogels, especially in the controlled delivery of therapeutic agents and tissue engineering, have been largely developed to date for significant complex applications [26]. A cross-related density can be used to alter the porous structure of hydrogels, so regulation of the release actions of various bioactive agents, such as proteins or narcotics [22]. Following are several important cases of hydrogen sensitivity in temperature for the supply of medications, genes, cells, or other treatment agents [19,28].

\section{Summary}

A surface alteration method focused on stimulating microgels was investigated to introduce moisture regulation properties for cotton fabric. Using BTCA as the cross-linker, poly-NiPAAm (PNCS) microgel was used to manufacture practical cotton. The pad-dry-cure process was applied. The WRC in the PNCS-treated cotton fabric improves by an increased NCS proportion. Determination of particle size in various temperatures $(20-40 \mathrm{C})$ and $\mathrm{pH}(4$, 7 , and 8) has confirmed the responsiveness of these nanoparticles.

\section{Funding}

This research received no external funding.

\section{Acknowledgments}

The authors are gratefully grateful to acknowledge to the faculty of Applied Arts, Benha University. Thankful are also acknowledge to National Research Centre (NRC).

\section{Conflicts of Interest}

The authors declare no conflict of interest.

\section{References}

1. Jocić, D.; Tourrette, A.; Lavrič, P.K. Biopolymer-based stimuli-responsive polymeric systems for functional finishing of textiles. In Biopolymers, Elnashar, M., Ed. Sciyo: 2010; 37-60, https://doi.org/10.5772/10257.

2. Hassabo, A.G.; Mohamed, A.L. Enhancement of thermo-regulating textile materials using phase change material (pcm). Evolution in Polymer Technology Journal 2019, 2.

3. Hassabo, A.G.; El-Naggar, M.E.; Mohamed, A.L.; Hebeish, A.A. Development of multifunctional modified cotton fabric with tri-component nanoparticles of silver, copper and zinc oxide. Carbohydr. Polym. 2019, 210, 144-156, https://doi.org/10.1016/j.carbpol.2019.01.066. 
4. Hassabo, A.G.; Shaarawy, S.; Mohamed, A.L.; Hebiesh, A. Multifarious cellulosic through innovation of highly sustainable composites based on moringa and other natural precursors. Int. J. Biol. Macromol. 2020, 165 141155, https://doi.org/10.1016/j.ijbiomac.2020.09.125.

5. Mohamed, A.L.; El-Naggar, M.E.; Hassabo, A.G. Preparation of hybrid nanoparticles to enhance the electrical conductivity and performance properties of cotton fabrics. Journal of Materials Research and Technology 2021, https://doi.org/10.1016/j.jmrt.2021.02.035.

6. Balakrishnan, B.; Mohanty, M.; Umashankar, P.R.; Jayakrishnan, A. Evaluation of an in situ forming hydrogel wound dressing based on oxidized alginate and gelatine. Biomaterials 2005, 26, 6335-6342, https://doi.org/10.1016/j.biomaterials.2005.04.012.

7. Risbud, M.V.; Karamuk, E.; Mayer, J. Designing hydrogel coated textile scaffolds for tissue engineering: Effect of casting conditions and degradation behavior studied at microstructure level. Journal of Materials Science Letters 2002, 21, 1191-1194, https://doi.org/10.1023/A:1016564201212.

8. Feil, H.; Bae, Y.H.; Feijen, J.; S.W.Kim. Mutual influence of ph and temperature onthe swelling of ionizable and thermosensitive hydrogels. Macromolecules 1992, 25, 5528-5530, https://doi.org/10.1021/ma00046a063.

9. Xu, H.-L.; Xu, J.; Zhang, S.-S.; Zhu, Q.-Y.; Jin, B.-H.; ZhuGe, D.-L.; Shen, B.-X.; Wu, X.-Q.; Xiao, J.; Zhao, Y.-Z. Temperature-sensitive heparin-modified poloxamer hydrogel with affinity to kgf facilitate the morphologic and functional. Drug Deliv 2017, 24, 867-881, https://doi.org/10.1080/10717544.2017.1333173.

10. Jocic, D.; Tourrette, A.; Glampedaki, P.; Warmoeskerken, M.M.C.G. Application of temperature and $\mathrm{pH}$ responsive microhydrogels for functional finishing of cotton fabric. Materials Technology 2009, 24, 14-23, https://doi.org/10.1179/175355509X417963.

11. Khattab, T.A.; Mohamed, A.L.; Hassabo, A.G. Development of durable superhydrophobic cotton fabrics coated with silicone/stearic acid using different cross-linkers. Materials Chemistry and Physics 2020, 249, https://doi.org/10.1016/j.matchemphys.2020.122981.

12. El-Zawahry, M.M.; Hassabo, A.G.; Abdelghaffar, F.; Abdelghaffar, R.A.; Hakeim, O.A. Preparation and use of aqueous solutions magnetic chitosan / nanocellulose aerogels for the sorption of reactive black 5. Biointerface Research in Applied Chemistry 2021, 11, 12380 - 12402, https://doi.org/10.33263/BRIAC114.1238012402.

13. Mohamed, A.L.; Hassabo, A.G. Review of silicon-based materials for cellulosic fabrics with functional applications. Journal of Textiles, Coloration and Polymer Science 2019, 16, 139-157, https://doi.org/10.21608/JTCPS.2019.18580.1030.

14. Mohamed, A.L.; Elmotasem, H.; Salama, A.A.A. Colchicine mesoporous silica nanoparticles/hydrogel composite loaded cotton patches as a new encapsulator system for transdermal osteoarthritis management. Int. J. Biol. Macromol. 2020, 164, 1149-1163, https://doi.org/10.1016/j.ijbiomac.2020.07.133.

15. Mohamed, A.L.; Soliman, A.A.F.; Ali, E.A.; Abou-Zeid, N.Y.; Nada, A.A. Hydrogel bioink based on clickable cellulose derivatives: Synthesis, characterization and in vitro assessment. Int. J. Biol. Macromol. 2020, 163, 888-897, https://doi.org/10.1016/j.ijbiomac.2020.07.068.

16. El-Sabour, M.A.; Mohamed, A.L.; El-Meligy, M.G.; Al-Shemy, M.T. Characterization of recycled waste papers treated with starch/organophosphorus-silane biocomposite flame retardant. Nord. Pulp Pap. Res. J. 2021, 36, 108-124, https://doi.org/10.1515/npprj-2020-0075.

17. Kulkarni, A.; Tourrette, A.; Warmoeskerken, M.M.C.G.; Jocic, D. Microgel-based surface modifying system for stimuli-responsive functional finishing of cotton. Carbohydr. Polym. 2010, 82, 1306-1314, https://doi.org/10.1016/j.carbpol.2010.07.011.

18. Niu, Y.; Chen, K.C.; He, T.; Yu, W.; Huang, S.; Xu, K. Scaffolds from block polyurethanes based on poly(varepsilon-caprolactone) (pcl) and poly (ethylene glycol) (peg) for peripheral nerve regeneration. Biomaterials 2014, 35, 4266-4277, https://doi.org/10.1016/j.biomaterials.2014.02.013.

19. Huang, G.; Hu, Z. Phase behavior and stabilization of microgel arrays. Macromolecules 2007, 40, 3749-3756, https://doi.org/10.1021/ma070253d.

20. Pan, Y.V.; Wesley, R.A.; Luginbuhi, R.; Dento, D.D.; Ratner, B.D. Plasma polymerized n-isopropylacrylamide: Synthesis and characterization of a smart ther-mally responsive coating. Biomacromolecules 2001, 2, 32-36, https://doi.org/10.1021/bm0000642.

21. Mukherjee, D., Azamthulla, M., Santhosh, S., Dath, G., Ghosh, A., Natholia, R., Anbu,J., Teja, B.V., Muzammil, K.M.,; Mukherjee, D.; Azamthulla, M.D.; Santhosh, S.; Dath, G.; Ghosh, A.; Natholi, R.; Anbu, J.; Tejad, B.V.; Muzammila, K.M. Development and characterization of chitosan-based hydrogels as wound dressing materials. Journal of Drug Delivery Science and Technology 2018, 46, 498-510, https://doi.org/10.1016/j.jddst.2018.06.008.

22. Bashari, A.; Hemmatinejad, N.; Pourjavadi, A. Surface modification of cotton fabric with dual-responsive pnipaam/chitosan nano hydrogel. Polym. Adv. Technol. 2013, 24, 797-806, https://doi.org/10.1002/pat.3145.

23. Huang, H.; Qi, X.; Chen, Y.; Wu, Z. Thermo-sensitive hydrogels for delivering biotherapeutic molecules: A review. Saudi Pharmaceutical Journal 2019, 27, 990-999, https://doi.org/10.1016/j.jsps.2019.08.001.

24. Zhao, Y.-L.; Stoddart, J.F. Azobenzene-based light-responsive hydrogel system. Langmuir 2009, 25, 84428446, https://doi.org/10.1021/la804316u.

25. Chen, Y.; Kang, S.; Yu, J.; Wang, Y.; Zhu, J.; Hu, Z. Tough robust dual responsive nanocomposite hydrogel as controlled drug delivery carrier of asprin. Journal of the Mechanical Behavior of Biomedical Materials 2019, 92, 179-187, https://doi.org/10.1016/j.jmbbm.2019.01.017. 
26. Bucio, E.; Burillo, G. Radiation grafting of ph and thermosensitive n-isopropylacrylamide and acrylic acid on to ptfe films by two-steps process. Radia. Phys. Chem. 2009, 76, 1724-1727, https://doi.org/10.1016/j.radphyschem.2007.02.109.

27. Tourrette, A.; Geyter, N.D.; Jocic, D.; Morent, R.; Warmoeskerken, M.M.C.G.; Leys, C. Incorporation of poly(n-isopropylacrylamide)/chitosan microgel onto plasma functionalized cotton fibre surface. Colloids and Surfaces A: Physicochemical and Engineering Aspects 2009, 352, 126-135, https://doi.org/10.1016/j.colsurfa.2009.10.014.

28. Ahmed, E.M. Hydrogel: Preparation, characterization, and applications: A review. Journal of Advanced Research 2015, 6, 105-121, https://doi.org/10.1016/j.jare.2013.07.006.

29. Tomme, S.R.V.; Storm, G.; Hennink, W.E. In situ gelling hydrogels for pharmaceutical and biomedical applications. Int. J. Pharm 2008, 355, 1-18, https://doi.org/10.1016/j.ijpharm.2008.01.057.

30. Hu, J.; Meng, H.; Li, G.; Ibekwe, S.I. A review of stimuli-responsive polymers for smart textile applications. Smart Materials and Structures 2012, 21, 24, https://doi.org/10.1088/0964-1726/21/5/053001.

31. Mondal, S. Phase change materials for smart textiles-an overview. Applied Thermal Engineering 2008, 28, 1536-1550, https://doi.org/10.1016/j.applthermaleng.2007.08.009.

32. Lavric, P.K.; Warmoeskerken, M.M.C.G.; Jocic, D. In Vapour transmission properties of a surface modified tex-tile material with poly-nipaam/chitosan microgel. Proceedings of 41 st international symposium on novelties in textiles (ISNT), Lubljana, Slovenia, 2010, 104-110.

33. Križman Lavrič, P.; Warmoeskerken, M.C.G.; Jocic, D. Functionalization of cotton with poly-nipaam/chitosan microgel. Part i. Stimuli-responsive moisture management properties. Cellulose 2012, 19, 257-271, https://doi.org/10.1007/s10570-011-9632-X.

34. Bashari, A.; Hemmatinejad, N.; Pourjavadi, A. Applications of stimuli responsive hydrogels: Atextile engineering approach. Journal of The Textile Institute 2013, 104, 1145-1155, https://doi.org/10.1080/00405000.2013.780787.

35. Qu, C.; Bao, Z.; Zhang, X.; Wang, Z.; Ren, J.; Zhou, Z.; Tian, M.; Cheng, X.; Chen, X.; Feng, C. A thermosensitive rgd-modified hydroxybutyl chitosan hydrogel as a 3D scaffold for bmscs culture on keloid treatment. Int. J. Biol. Macromol. 2019, 125, 78-86, https://doi.org/10.1016/j.ijbiomac.2018.12.058.

36. Gann, M.J.M.; Higginbotham, C.L.; Geever, L.M.; Nugent, M.J.D. The synthesis of novel ph-sensitive poly (vinyl alcohol) composite hydrogels using a freeze/thaw process for biomedical applications. Int. J. Pharm 2009, 372, 154-161, https://doi.org/10.1016/j.ijpharm.2009.01.008.

37. Mohamed, A.L.; Hassabo, A.G. Cellulosic fabric treated with hyperbranched polyethyleneimine derivatives for improving antibacterial, dyeing, ph and thermo-responsive performance. Int. J. Biol. Macromol. 2021, 170, 479489, https://doi.org/10.1016/j.ijbiomac.2020.12.198.

38. Mondal, S.; Hu, J.L. Water vapor permeability of cotton fabrics coated with shape memory polyurethane. Carbohydr. Polym. 2007, 67, 282-287, https://doi.org/10.1016/j.carbpol.2006.05.030.

38. Okada, Y.; Tanaka, F. Cooperative hydration, chain collapse, and flat lcst behavior in aqueous poly(nisopropylacrylamide) solutions. Macromolecules 2005, 38, 4465-4471, https://doi.org/10.1021/ma0502497.

39. Bashari, A.; Hemmatinejad, N.; Pourjavadi, A. Applications of stimuli responsive hydrogels: Atextile engineering approach. Journal of The Textile Institute 2013, 104, 1145-1155, 10.1080/00405000.2013.780787.

40. Mohamed, A.L.; Hassabo, A.G. Flame retardant of cellulosic materials and their composites. In Flame retardants, Visakh, P.M.; Arao, Y., Eds. Springer International Publishing: 2015; pp 247-314, http://dx.doi.org/10.1007/978-3-319-03467-6_10.

41. Nada, A.A.; Hassabo, A.G.; Mohamed, A.L.; Mounier, M.M.; Abou Zeid, N.Y. Liposomal microencapsulation of rodent-repelling agents onto jute burlaps: Assessment of cytotoxicity and rat behavioral test. JAPS 2016, 6, 142-150, http://doi.org/10.7324/JAPS.2016.60822.

42. Visakh, P.; Arao, Y. Flame retardants: Polymer blends, composites and nanocomposites. Springer: 2015.

43. Abo-Shosha, M.H.; Nassar, F.A.; Haggag, K.; El-Sayed, Z.; Hassabo, A.G. Utilization of some fatty acid/peg condensates as emulsifiers in kerosene paste pigment printing. Resarch Journal of Textile and Apprael 2009, 13, 65-77, http://dx.doi.org/10.1108/RJTA-13-01-2009-B007.

44. El-Zawahry, M.M.; Abdelghaffar, F.; Abdelghaffar, R.A.; Hassabo, A.G. Equilibrium and kinetic models on the adsorption of reactive black 5 from aqueous solution using eichhornia crassipes/chitosan composite. Carbohydr. Polym. 2016, 136, 507-515, http://dx.doi.org/10.1016/j.carbpol.2015.09.071.

45. Ibrahim, N.A.; El-Sayed, Z.M.; Fahmy, H.M.; Hassabo, A.G.; Abo-Shosha, M.H. Perfume finishing of cotton / polyester fabric cross-linked with dmdheu in presence of some softeners. Resarch Journal of Textile and Apprael. 2013, 17, 58-63, https://doi.org/10.1108/RJTA-17-04-2013-B007.

46. Mohamed, A.L.; El-Naggar, M.E.; Shaheen, T.I.; Hassabo, A.G. Novel nano polymeric system containing biosynthesized core shell silver/silica nanoparticles for functionalization of cellulosic based material. Microsys. Technol. 2016, 22, 979-992, http://doi.org/10.1007/s00542-015-2776-0.

47. Mohamed, A.L.; Er-Rafik, M.; Moller, M. Suitability of confocal raman microscopy for monitoring the penetration of pdms compounds into cotton fibres. Carbohydr. Polym. 2013, 96, 305-313, http://dx.doi.org/10.1016/j.carbpol.2013.03.087. 
48. Mohamed, A.L.; Er-Rafik, M.; Moller, M. Supercritical carbon dioxide assisted silicon based finishing of cellulosic fabric: A novel approach. Carbohydr. Polym. 2013, 98, 1095-1107, http://dx.doi.org/10.1016/j.carbpol.2013.06.027.

49. Waly, A.I.; Abou-Zeid, N.Y.; Marie, M.M.; El-Sheikh, M.A.; Mohamed, A.L. Special finishing of cotton to impart flame-retardancy, easy care finishing and antimicrobial properties. RJTA 2009, 13, 10-26,

50. Waly, A.I.; Marie, M.M.; Abou-Zeid, N.Y.; El-Sheikh, M.A.; Mohamed, A.L. Processes of dyeing, finishing and flame retardancy of cellulosic textiles in the presence of reactive tertiary amines. RJTA 2012, 16, 66 - 84, https://doi.org/10.1108/RJTA-16-03-2012-B007.

51. Ebrahim, S.A.; Hassabo, A.G.; Othman, H. Natural thickener in textile printing (a mini review). Journal of Textiles, Coloration and Polymer Science 2021, 18, 55-64, https://doi.org/10.21608/jtcps.2021.69482.1051.

52. El-Sayed, E.; Hassabo, A.G. Recent advances in the application of plasma in textile finishing. Journal of Textiles, Coloration and Polymer Science 2021, 18, 33-43, https://doi.org/10.21608/jtcps.2021.67798.1050.

53. Hamdy, D.M.; Hassabo, A.G.; Othman, H. Recent use of natural thickeners in the printing process. Journal of Textiles, Coloration and Polymer Science 2021, 18, 75-81, https://doi.org/10.21608/jtcps.2021.69754.1053.

54. Kamel, M.Y.; Hassabo, A.G. Anti-microbial finishing for natural textile fabrics. Journal of Textiles, Coloration and Polymer Science 2021, 18, 83-95, https://doi.org/10.21608/jtcps.2021.72333.1054.

55. Ragab, M.M.; Hassabo, A.G.; Othman, H. Synthetic thickeners in textile printing. Journal of Textiles, Coloration and Polymer Science 2021, 18, 65-74, https://doi.org/10.21608/jtcps.2021.69743.1052.

56. Yousef, M.L.; Hassabo, A.G. Environmentally friendly inorganic materials for anti-flammable cotton fabrics. Journal of Textiles, Coloration and Polymer Science 2021, 18, 97-110, https://doi.org/10.21608/jtcps.2021.73914.1058.

57. Diaa, M.; Hassabo, A.G. Self-cleaning properties of cellulosic fabrics (a review). Biointerface Research in Applied Chemistry 2022, 12, 1847 - 1855, https://doi.org/10.33263/BRIAC122.18471855.

58. Zayed, M.; Othman, H.; Ghazal, H.; Hassabo, A.G. Psidium guajava leave extract as reducing agent for synthesis of zinc oxide nanoparticles and its application to impart multifunctional properties for cellulosic fabrics. Biointerface Research in Applied Chemistry 2021, $11, \quad 13535 \quad$ - 13556 , https://doi.org/10.33263/BRIAC115.1353513556. 